services are 'multidisciplinary', but what has caused special problems for child psychiatrists is that they are frequently part of 'multi-agency' teams in which the primary responsibility for the service is unclear.

In the coming months, with the abolition of the ILEA drawing near, child psychiatrists in London child guidance units previously administered by ILEA's 'Medical Department', would do well to clarify their position with their employing health authorities. Will the 'day-to-day' running of the clinics be the responsibility of the health authority or the local authority's education or social services department? How will the statistical returns be made? How will the priorities for work be established? What authority will have ownership of the notes?

For some clinics, there will be strong arguments for total integration with the local district child psychiatry service; for others a clearer consultative or collaborative model may emerge. What should be recognised is that with this re-organisation there arises an opportunity for providing a better service, but also a risk of loss of resources. 'Community care' is easily marginalised.

King's College Hospital London SE5

\section{Will you become a PENpal?}

DeAR SIRS

Later in the year I am hoping to launch a Quarterly Video News Service for Psychiatrists provisionally entitled Psychiatry - Education and News.

Most medical specialities have some form of video news service, usually supported by advertising. These programmes appear to be highly regarded and valued, particularly by those in training. In this respect, there is no reason to suppose that psychiatrists are any different. It has to be recognised that the amount of potential advertising support is likely to be less than for programmes aimed at GPs for example. This is because there are fewer psychiatrists and they spend less on drugs and equipment. In spite of the potential financial constraints it is possible to make a useful educational production, although in the long run it may prove necessary to charge a small amount.

The possible format I have in mind might be 20 to 30 minutes of regular items, each lasting five to seven minutes, followed by an illustrated lecture lasting say 40 minutes. Some of the short items might include the following: (i) What's new since you left medical school; (ii) short clips from teaching tapes and comments from a reviewer; (iii) short report from quarterly conference; (iv) what I do in my job: pitched at SHOs and registrars describing work in various sub-specialties; (v) teaching tape - consensus views on the management of various conditions; (vi) 'letters page': taking sent-in video clips and letters; (vii) interviews with established leaders within psychiatry and interviews of public figures.

Several possibilities exist for distribution: (i) via cassette on a request only basis; (ii) sent unsolicited; (iii) satellite transmission. In the long run this last option may prove satisfactory but there are a number of important logistic and technical problems which will have to be resolved first.

I am writing at this stage because I would like to assess potential interest in the venture and to see whether there are people willing to co-operate. I do not think it will be a money-spinner but with support and goodwill it could become an important contribution to education.

In the first instance I would be grateful if people could write to me at the Department of Psychiatry, St George's Hospital, Blackshaw Road, Tooting, London, SW17 ORE.

\section{St George's Hospital}

London SW17

ANDRew MaCaUley

\section{'Let the Old Man Drink'}

\section{DEAR SIRS}

Drs Al-Bachari and Acharyya (Psychiatric Bulletin, March 1989, 13, 149) ask for readers' comments on 'Let the Old Man Drink'. The first point is that there are many old women who drink to excess! Edwards et al (1973) report a male: female ratio of $1: 1.3$, a ratio I confirmed (Malcolm, 1984). It must be remembered that females predominate in the elderly population and society may cover up old ladies' bad habits even more than old men's. Perhaps one day the elderly ratio will approach the $1: 1$, as in younger groups

Alcohol problems in the elderly are common, $6 \%$ was quoted by Mishara \& Kastenbaum (1980) although they admitted denial was relevant. I reported $10 \%$ in a study of 223 new patients seen at home between 1978 and 1981 (Malcolm, 1984). Only half these cases were previously known to the family doctor. Figures over $10 \%$ are widely accepted now. While many elderly suffer physical, mental, social and financial harm from alcohol, very many others benefit from its judicious and social use. It is our responsibility to be sure into which group our patient falls. The idea of 'it's too late to help, let him have it' is discredited in a charming handbook by Kinney \& Leaton (1978). The concept of recent or remote onset drinking is a helpful one (Rosin \& Glatt, 1971). Recent onset suggest a treatable cause for the problem, e.g. a response to bereavement, isolation, pain etc. The remote onset implies that a long-term drinker has achieved old age, he must aim for sobriety. It is essential to consider the source of alcohol in the elderly. Housebound or frail elderly may have more than one supplier, relatives who give in to 
blackmail (Droller, 1964) or other visitors who fail to see a problem. Each may think that he is acting alone. Delivery vans and taxis do deliver from off-licences and leaflets advertise this service. For the first time ever, I have this month been indirectly referred a problem drinker by a conscientious van driver! The patient told me in discussion "there are lots of other branches" (of the off-licence chain).

"Physiological changes of ageing make the elderly more vulnerable to alcohol": while this is true it is believed that the breakdown of ethanol by the enzyme dehydrogenase is not changed in the elderly. However the concentration of alcohol in the body is greater in the elderly, for the same dose. This is because the lipid phase increases in the elderly, consequently there is proportionally less water for the alcohol to enter. Further, the elderly alcoholic is often already light-weight. This reduced water phase is even more marked in women than men, perhaps explaining the rapidity of decline often seen in women with alcohol problems. These points are demonstrated and developed in 288 interesting pages of Alcoholism in the Elderly, Social and Biomedical Issues (Hartford \& Samorajski, 1984). This book also discusses in some detail alcohol abuse as a cause of dementia, an association supported by King (1986). Brown (cit Kelynack, 1906) in his The Prevention of Senility says "... there can be no question that an excess of it (alcohol) does make men old before their time". At a more practical level Age Concern together with Alcohol Concern have produced a comprehensive and helpful leaflet, Alcohol and Older People (1988).

Drs Al-Bachari and Acharyya quote from Proverbs; allow me my favourite quote from Dr Kelynack (1906) "With declining mental powers and waning bodily vigour neurasthenic conditions are liable to be established which may tempt the unwary and ignorant to seek relief from the narcotising action of alcohol. When the judgement is dulled and the will enfeebled it is easy for the subject advanced on life's downhill path to quicken all unwittingly his steps, and so unknowingly and unperceived hasten his descent into the silent valley".

\section{Clatterbridge Hospital}

Wirral, Merseyside

\section{References}

Age Concern. (1988) Alcohol and Older People. Age Concern England, 60 Pitcairn Road, Mitcham, Surrey, CR4 3LL.

Droller, H. (1964) Some aspects of alcoholism in the elderly. Lancet, 2, 137-139.

Edwards, G., Hawker, A., Hensman, C., Peto, J. \& Williamson, V. (1973) Alcoholics known or unknown to agencies: epidemiological studies in a London suburb. British Journal of Psychiatry, 123, 169-183.
HARTFORD, J. T. \& SAMORAJSKI, T. (eds.) (1984) Alcoholism in the Elderly: Social and Biomedical Issues. New York: Raven Press.

KelYNACK, T. N. (1906) The Alcohol Problem in its Biological Aspect, London: Richard J. James.

KING, M. B. (1986) Alcohol abuse and dementia. International Journal of Geriatric Psychiatry, 1, 31-36.

KINNEY, J. \& LEATON, G. (1978) Loosening the Grip: a Handbook of Alcohol Information. St. Louis: C. V. Mosby.

MALCOLM, M. T. (1984) Alcohol and drug use in the elderly visited at home. International Journal of the Addictions, 19, 411-418.

Mishara, B. L. \& KASTEnbaum, R. (1980) Alcohol and Old Age. New York: Grune \& Stratton.

Rosin, A. J. \& GlatT, M. M. (1971) Alcohol excess in the elderly. Quarterly Journal of Studies in Alcohol, 32, 53-59.

\section{Administration of rectal diazepam}

DeAr SIRS

In the health district in which I work, there have recently been difficulties in the administration of rectal diazepam to patients who require this for the acute management of epileptic seizures. This has arisen because of a directive from our local social services department which instructs its staff members that they are not indemnified against its administration. As none of the social services day or residential provisions at present employ clinical staff, this has led to an unsatisfactory situation. The suggestion has been made that an ambulance be called if a person has a severe or prolonged seizure, but this is not a sufficiently rapid response. It has also been suggested that clinically trained staff be jointly appointed to centres by health and social services.

I am writing this letter in an attempt to discover whether similar problems have occurred in the catchment areas of any other consultants in the psychiatry of mental handicap. I will be most grateful to hear from them.

Mental Handicap Unit

ANTHONY KEARNS

Chase Farm Hospital

Enfield, Middlesex, and

Academic Department of Psychiatry

Royal Free Hospital, London NW3

\section{Diary keeping by junior doctors}

\section{DeAr Sirs}

We would like to add to the comments made by Dr Adams (Psychiatric Bulletin, January 1989, 13, 37). He had noted a reduction in the burden of on-call by communicating with other juniors via a diary. During our study of on-call experience (Donnelly \& Rice, 1989) we felt that our burden was lightened 